Article

\title{
Could a Smart City Ameliorate Urban Traffic Congestion? A Quasi-Natural Experiment Based on a Smart City Pilot Program in China
}

\author{
Yuhui Guo $^{1}{ }^{\mathbb{D}}$, Zhiwei Tang ${ }^{2, *}$ and Jie Guo ${ }^{2}$ \\ 1 School of Management and Economics, University of Electronic Science and Technology of China, \\ Chengdu 611731, China; gyhui322@hotmail.com \\ 2 School of Public Affairs and Administration, University of Electronic Science and Technology of China, \\ Chengdu 611731, China; carriedreams@126.com \\ * Correspondence: tangzw@uestc.edu.cn
}

Received: 4 February 2020; Accepted: 11 March 2020; Published: 15 March 2020

\begin{abstract}
More countries and regions are joining the bandwagon of smart city construction, which is an important strategy and innovative urban governance concept to solve the problem of rapid urbanization. This paper examines whether smart city innovation is able to ameliorate the traffic congestion faced by a large number of cities. Using panel data for 187 prefecture-level cities in China from 2008 to 2017, this paper tests the effect of implementation of a smart city on urban traffic congestion with the difference-in-difference method. The results show that, firstly, the construction of smart cities have significantly reduced the degree of urban traffic congestion and improved the quality and capacity of public transport. Secondly, information technology and urban innovation are the main mechanisms for smart city implementation to improve urban traffic problems. Thirdly, the improvement effect of smart city implementation on traffic management shows an increasing marginal effect over time. By overcoming the estimation bias in previous studies, this study accurately analyzes the positive role and dynamic effect of smart city construction on traffic improvement. It augments the literature of program evaluation and assessment of smart city implementation. By examining how to improve traffic congestion, it offers some insights that could inspire governments to build smarter cities with better traffic.
\end{abstract}

Keywords: smart city; traffic congestion; technology; innovation

\section{Introduction}

Urbanization is an inevitable trend of social development. It not only brings potentiality, new sources for the accumulation of social wealth, and the improvement of public life quality, but it also promotes great changes in human production patterns and lifestyles [1]. Although different countries across the world have taken different urban development paths to propel urban modernization forward based on their own national conditions, they cause analogical urban crowding results, which has broken out a series of urban diseases. According to a United Nations publication, 55\% of the world's population lives in urban areas, a proportion that is expected to increase to $68 \%$ by 2050 [2]. It is undeniable that urbanization has greatly promoted the development of society, economy, science, and technology, but it has also brought great challenges to the sustainable development of human beings at the same time. Rapid economic growth and increasing urbanization has dramatically increased the size and proportion of China's urban population [3]. Problems concomitant to rapid urban growth, mainly urban traffic congestion, have also become increasingly serious. In China, the number of private cars has increased from 70 million in 2010 to 320 million in 2018. Fifty-eight cities have more than one 
million cars [4], and seven cities have more than three million. The sprawling growth of cars, large population, and lagging road infrastructure construction continue to exacerbate urban carrying loads and road traffic burdens, causing a large number of cities in China to experience traffic congestion. Taking Beijing as an example, the average daily congestion duration in 2017 was 2.6 hours, while it was only 0.9 hours in 2009 [5]. Inrix, an American traffic data analysis company, released the global traffic scorecard. According to the survey, the United States accounts for 11 of the 25 most congested cities in the world. Car owners in Los Angeles spend an average of 104 hours in traffic jams every year during peak hours. The estimated direct or indirect economic losses caused by traffic jams to American car owners reach $\$ 300$ billion, with an average of $\$ 1400$ per driver [6]. Countries (led by Thailand, Colombia, and Indonesia) also have serious traffic congestion problems in the process of urbanization. Some studies have pointed out that urban traffic congestion not only wastes public road resources, but also increases the probability of traffic accidents. In the long run, it will also seriously reduce the efficiency of urban production and operation, affect the development of the urban business environment, and restrict rapid economic development. Meanwhile, increasing energy consumption and exhaust emissions have exacerbated the damage to urban ecologies [7-9]. Therefore, investigating the factors causing traffic congestion, seeking ways to reduce traffic congestion, and strengthening the research on the mechanisms of improving urban traffic congestion are not only of important theoretical significance, but also of policy guidance value, to help the government formulate traffic policies, promote economic growth, and increase public welfare.

At present, a large number of scholars have discussed the causes of urban traffic congestion from different perspectives. Studies indicate that increasing traffic demand, changes in travel modes, rapid population growth, unexpected catastrophic weather, delayed urban traffic planning, lack of traffic management, and imbalances in supply and demand for public transport are all important causes of urban traffic congestion [10-13]. Considering the current situation of traffic congestion in China in light of this research, the imbalance between the rapid urbanization process and the development of various social systems is one of the main factors that exacerbate urban traffic congestion in China. Feng et al.'s empirical analysis of panel data from cities in China shows that urbanization has an inverted U-shaped relationship with traffic density in surrounding cities; thus, causing serious regional traffic congestion [14]. Anthony Downs argues that urban development measures that rely solely on increasing road supply to combat congestion are also inefficient, because new road infrastructure will cause new traffic flows, backward urban traffic planning and design, along with poor traffic management mode, which will also exacerbate traffic congestion [15]. Meanwhile, urbanization also attracts a large number of migrants, leading to a continuous increase in population concentration and road traffic density [16]. The above research points out the negative effects of urbanization on traffic congestion, but ignores the role of new urban development models and key information technologies in improving transportation. This paper will further discuss this issue based on previous studies. We cannot help but think, can the vicious cycle of urban development and traffic congestion be broken through the deployment of innovative technologies and the reform of governance models, given that traditional urban development models have failed to address the traffic congestion cycle?

A "smart city"-a new urban governance model and governance concept-promises to make full use of information and communication technologies (ICTs) to sense, analyze, and integrate the core systems of urban operations, and make intelligent responses to activities, such as people's livelihood, environmental protection, public safety, and urban services, creating better urban life for mankind [17]. With the introduction of the concept of a smart city, more countries and regions have joined the bandwagon of smart city planning and construction, integrating the dual innovations of technology and governance models. In 2005, the European Union (EU) officially implemented the "i2010" strategy and launched the construction of a smart city network in Europe. At the same time, the UK issued the "Digital Britain" plan, while Germany launched the "smart bay" project. In Asia, through the "smart country" plan, Singapore uses information and communication technology to achieve a high degree of integration of government, enterprises, individuals, and infrastructure, 
delegating the blueprint of a data driven smart country. Japan puts forward the concept of "Society 5.0 ", emphasizes the advanced fusion of cyberspace and physical space, and makes a detailed layout of urban development and technological innovation. In the United States, the White House Smart Cities Initiative, released by the federal government, has adopted 25 innovative technology collaborations to solve problems, such as traffic congestion, urban crime, and fighting slow economic growth and lagging urban services. The Chinese government first proposed the smart city construction plan in their national policy in 2012. The plan clearly defined the application areas of a smart city, including the Internet of Things (IOT), and launched the smart city pilot program, setting off a wave of innovation in China's urban governance model. As a city development strategy in the new era, smart city differs from traditional urban governance modes by the characteristics of thorough perception, deep interconnection, and intelligent applications, so as to solve urban diseases through social governance reform and technological innovation and development, providing new ways to improve urban traffic congestion [17,18].

Have smart city initiatives over the past decade effectively reduced urban traffic congestion? Has the problem of traffic congestion in various cities been alleviated by the technological changes and government innovations brought by smart cities, thereby, promoting sustainable development of cities? So far, scholars have mainly studied the positive effects of smart cities from the perspective of energy consumption and environmental protection [19,20], or analyzed the application of smart cities in the field of transportation through typical application cases [21,22], but few scholars have conducted empirical tests on the ability of the "smart city" to solve traffic congestion.

This paper uses the Difference in Difference (DID) approach and China's urban panel data to study the improvement and influence mechanism of a smart city on traffic congestion. The main contributions of this paper are as follows: first, through scientific research methods, this paper identifies the impact mechanism and increasing marginal effects of smart cities on traffic improvement, filling a gap in the literature on smart city impacts and providing guidance to governments to build smart cities. Second, it utilizes new panel data from Chinese cities in the past 10 years and uses Propensity Score Matching (PSM) to overcome drawbacks of previous research, such as estimation bias; thus, improving the robustness of the conclusions.

The remainder of the paper is structured as follows. In the second part, we elaborate the background and theoretical hypothesis of the smart city policy. The third part introduces the research design, data, variables, etc. The fourth part reports the process and results of empirical testing. The fifth part summarizes the findings and relevant policy implications.

\section{Policy Background and Research Hypotheses}

\subsection{Smart City and China's Smart City Pilot}

The concept of the smart city is derived from the smart earth concept proposed by International Business Machines (IBM) [23]. It embeds sensors and smart sensors in every corner of the city, forms the Internet of Things, and integrates relevant information through supercomputers and cloud computing. The smart city promises to realize the deep integration of industrialization, informatization, and urbanization, alleviate urban problems, strengthen urban management, and improve the quality of urban life. Since the inception of the concept, scholars have been exploring the theoretical and practical implications of the smart city. Along with similar concepts, such as the intelligent city, digital city, and information city, the smart city highlights the commonality and diversity of its conceptualizations [24-26]. For one thing, the smart city uses advanced ICTs to intelligently transform urban infrastructure to interconnect and integrate urban infrastructures and manage them more effectively [27]. For another, the smart city is characterized by innovation. It does not visualize a purely technical solution to urban problems; it seeks to achieve efficient decision-making and resource integration through new forms of urban management, social organization, and public participation $[28,29]$. 
Along with the tide of smart city programs initiated in the United States, the United Kingdom, Germany, Japan, and other countries around the world, local governments in China too have explored smart city plans and a number of smart cities have emerged [30]. However, due to the lack of thoughtful design and the blind pursuit of new concepts, the development of Chinese smart cities has been slow with little effect. In 2012, in order to promote the healthy development of smart cities, the Chinese government initiated a pilot program of a national smart city construction, and promulgated the "Interim Measures for the Administration of National Smart City Pilots" and "National Smart City (District, Town) Pilot Indicator System." Collectively, these two documents seek to provide development plans for local governments through technical standards, industry standards, and financial support. Since then, a number of smart city programs have been implemented in China, promising a significant and profound impact on all aspects of China's urban development.

\subsection{Research Hypotheses}

From a technical point of view, the smart city mainly uses data, networks, intelligent algorithms and transportation infrastructure to alleviate urban traffic problems [31]. First, it mines and utilizes traffic data resources through road network monitoring facilities, high-definition cameras, bus cards, Electronic Toll Collection (ETC), and other transportation infrastructure. A full range of information such as people flow, vehicles, and roads, can be recorded in real time, directly, accurately, and continuously so as to realize the automatic monitoring of urban traffic operation status, which in turn enables a series of smart applications [32,33]. Second, the construction of the network and cloud platform provides a platform for accessing digital resources. The network technology, represented by the Internet of Things (IOT), helps to gather data information from all sides of the city; coupling these database networks is the key to achieving maximum data utilization. The rapid development of $5 \mathrm{G}$ networks, high-speed data transmission will provide further opportunities for more smart city applications [34]. Third, intelligent algorithms based on artificial intelligence are the core force to improve traffic congestion in smart cities. Through intelligent algorithm analysis, the dynamic changes of urban traffic can be monitored through visualization. Abnormal changes in traffic patterns are noted in real-time, assisting the government in making traffic management decisions, providing road guidance tips to citizens, and improving the efficiency and resilience of urban traffic. For example, Vehicular Ad Hoc Network (VANET), an intelligent system, can maintain the dynamic timing of traffic signals by sensing traffic density, realize vehicle shunting without manual intervention, and minimize traffic congestion with sensors supporting the IOT [35,36].

The construction of smart city facilitates innovation at all levels, from individual behavior to government re-structuring and institutional planning [37]. For example, with effective, real-time visualization of traffic patterns, public travel no longer relies on paper maps or personal memories, but instead on the optimized routes suggested by electronic navigation systems, avoiding roads or areas with heavy traffic. Meanwhile, the construction of smart cities has also expanded the channels for citizens to participate in traffic governance. For example, traffic accidents or road conditions can be reported through traffic apps, so that the government can allocate repair and rescue resources in a timely manner [38-40]. In addition, in order to fully utilize the technological applications and risks brought by the construction of smart cities, the organization of government also needs to adapt to innovation and reform. The organizational structure of government departments may be changed to strengthen the cross-department sharing of data and information, as well as the cooperation between departments [41]. Finally, smart city traffic intelligent applications may need to be integrated into the existing urban traffic governance systems to ensure the legality of traffic governance and citizens' privacy rights. For example, innovative systems, such as the Internet of Vehicles, may collect data, such as vehicle speed and vehicle operations, using Global Positioning System (GPS) and sensors located in the car. This information is transmitted to the urban traffic brain through Internet technology to monitor road traffic conditions and intelligently adjust the cycle of signal lights (to better serve to alleviate traffic congestion) [42-47]. However, this information can also be used to assess driver 
insurance risks, with adverse consequences for privacy rights. Systems and protocols for the use of such information may need to be developed.

Based on the above discussion, the following hypotheses are proposed:

Hypothesis 1 (H1): smart city construction improves urban traffic congestion.

Hypothesis 2a (H2a): smart city construction improves urban traffic congestion through technological change.

Hypothesis $\mathbf{2 b}$ (H2b): smart city construction improves urban traffic congestion through innovation effect.

We further analyze the dynamic effect (time trend) of smart city construction on traffic improvement. First, the construction of a smart city is a complex system project that involves a wide range of fields. Municipal governments may choose to emphasize a certain field according to the current state of urban development and production structure. Therefore, smart transportation may not be the first choice for all cities [48]. Second, after being established as a smart city pilot, the city will need to initiate a series of planning and infrastructure construction, which may require some time for the optimal effect to be achieved.

Just as fiscal or industrial policies have effects that manifest only over the long-term, smart city programs, too, may impact traffic congestion only over time [49]. However, as smart city construction proceeds, massive amounts of valuable traffic data are collected, as well as intelligent application terminals, and infrastructure represented by artificial intelligence and IoT are deployed. With the continuous accumulation and iteration of data and technology, and as the corresponding facilities and industrial operations continue to mature, the marginal utility of smart cities will gradually increase, with cumulative impacts on traffic management. Therefore, the following hypothesis is proposed:

Hypothesis 3 (H3): the improvement effect of smart city construction on urban traffic congestion has a dynamic effect, and it gradually increases over time.

Next, we consider the heterogeneity analysis of the urban development characteristics of the smart city. The construction of a smart city mainly relies on emerging information technologies, such as IOT, big data, cloud computing, and artificial intelligence to enhance the ability to sense, integrate, analyze, and apply social environmental data. However, the construction of a smart city to alleviate traffic congestion through the above technical capabilities is not accomplished independently by a single system, but must be the integrative result of the systemic operation of the whole city based on the combination of urban development characteristics and resource endowments.

First, we take the impact of human capital on smart city construction into consideration. The development of new, high-tech industries driven by smart city innovation depends to some extent on a higher level of human capital. A workforce with higher education and technical skills can better transform knowledge into productivity and production results; thereby, promoting the impact and effectiveness of smart cities. At the same time, a public with better education and technology literacy can actively and quickly adapt to changes in traditional lifestyles brought about by new ICTs, such as ETC, route optimization navigation, and face recognition. The data resources generated by these technologies can accordingly improve the accuracy of smart city algorithms [50]. Therefore, human capital level will better support the construction of smart city, and then strengthen its effect on improving urban transportation.

Second, the effect of smart city construction also depends on public travel needs. In some studies, heterogeneity analysis is generally based on the size of the urban population. However, among the factors that cause traffic congestion, the imbalance of occupation and residence has been generally accepted, that is, the spatial separation of places of employment and residential areas in cities. In other words, the excessively large number of workers in the process of commuting to and from their residence and their workplace creates an overloaded and flexible commuting demand for urban traffic, 
resulting in congestion during rush hours. As a result, the size of the working population tends to better reflect the travel needs of a city. Therefore, in cities where public travel demand is high, the government is under much pressure to build a smart city, which in turn promotes the improvement of traffic congestion.

Finally, we analyze the impact of the development level of urban public transportation on the improvement effect of smart city transportation. Public transportation is the foundation of a sound urban public transport system, and is one of the common strategies to alleviate urban traffic congestion [51]. A well-developed public transportation system provides opportunity for the transportation departments to use information technology, such as IOT, big data, and cloud computing to collect and analyze real-time urban public transportation operations and public travel conditions $[10,52,53]$. In other words, relying on urban public transportation to build a smart city can promote the intelligent dispatch of urban public transportation, improve the level and efficiency of public transportation operation services; thus, be more conducive to improving urban traffic congestion. Therefore, the presence of a sound public transportation system can strengthen the impact of smart city construction on urban transportation problems.

Based on the above discussion, the following hypotheses are proposed:

Hypothesis 4a (H4a): for cities with high level of human capital, smart city construction will have a stronger effect on improving urban traffic congestion.

Hypothesis $4 \mathbf{b}(\mathbf{H} 4 \mathbf{b})$ : for cities with large public travel needs, smart city construction will have a stronger effect on improving urban traffic congestion.

Hypothesis 4c (H4c): for cities with better public transportation, smart city construction will have a stronger effect on improving urban traffic congestion.

\section{Data and Empirical Strategy}

\subsection{Econometric Strategy}

In order to test the improvement effect of smart city pilots on urban traffic quality, we can compare the differences of urban traffic quality before and after the smart city pilot to judge the mitigation effect of this policy on traffic congestion (Single-Difference method). However, the conclusion of this method may be inaccurate, because there are many other factors that will ease urban traffic congestion. For example, other national policies issued in the same period may also enable those cities that have never carried out the construction of smart cities to obtain traffic development; thus, improving the urban traffic congestion to a certain extent. However, if cities with smart city pilots are regarded as the experimental group and the non-pilot cities as the control group, the direct comparison between the experimental group and the control group will make the improvement effect of smart city on traffic congestion overestimated. Therefore, the effect of a smart city pilot needs to be evaluated under a more scientific difference-in-difference method (DID).

Heckman first proposed the DID model, which is to identify the processing effect of public policy by using the dual differences of horizontal units and time series brought by exogenous public policy [54]. China carried out the first National Smart City pilot in 2012, which provided a quasi-natural experiment to carry out a DID analysis. A quasi-natural experiment utilizes the exogenous impact of policy to eliminate the endogenous problems in the research process. If the selection of cities for smart city pilots are completely exogenous, then the quasi-natural experiment based on the pilot can solve the endogeneity problem well. Indeed, the selection of pilot cities is based on the overall eligibility of the city based on a long list of criteria, not on the urban traffic quality alone. However, as we show later, pilot and non-pilot cities had the same level of traffic congestion problems when evaluated at the pre-implementation baseline, which largely eliminates our concern that cities with less traffic 
congestion are more likely to enter the pilot list. Based on the above analysis, this paper uses the DID method to test the impact of smart city construction on urban traffic congestion using the opportunity for the quasi-natural experiment provided by China's smart city pilot in 2012.

According to the DID model, we take the city with the smart city pilot as the treated group, while the one without the pilot as the control group. By comparing the differences in traffic congestion levels of all samples before and after the smart city pilot, and comparing the differences between the treated and the control group, we can get the net effect of the smart city pilot on urban traffic congestion. If the urban traffic quality of the experimental group is higher than that of the control group after the pilot, then we have reason to think that the construction of smart city improves the urban traffic quality. Following the literature, we defined the average treatment effect of urban traffic on the smart city pilot as:

$$
\mathrm{TP}_{\text {it }}=\beta_{0}+\beta_{1} \text { Treat }_{\mathrm{i}} \times \text { Post }_{\mathrm{t}}+\gamma \mathrm{Ctr}_{\mathrm{it}}+\eta_{\mathrm{i}}+v_{\mathrm{t}}+\varepsilon_{\mathrm{it}}
$$

In this specification, TP stands for the traffic congestion level of the city (i) and year ( $t$ ). Ctr represents a set of control variables at the city level, including foreign direct investment, the degree of industrialization, economic development, etc. Treat is a city dummy variable equal to 1 if the observation is a pilot smart city, while Post is a time dummy variable equal to 1 after the year 2012. The key parameter that we need to estimate is $\beta_{1}$, which is the net effect of the smart city pilot on the improvement of urban traffic congestion. If $\beta_{1}$ is significantly positive, the level of urban traffic congestion in the treated group is higher than that in the control group, and the construction of a smart city promotes the improvement of urban traffic congestion. $\eta$ denotes city fixed effect, which is used to control the characteristic variables of the city that does not change with time, such as the geographical characteristics of the city. $v$ denotes time-fixed effect, which is used to control the characteristic variables of the time that does not change with the city, such as the impact of the national macro policy. The term $\varepsilon$ is the error component.

\subsection{Variable and Data}

Dependent variable (TP). The measurement of urban traffic congestion has always been a hot issue in the academic field. Different scholars have proposed different measurement standards and models, but mainly combining urban road network density, total population, traffic flow, road occupancy, number of buses, and other indicators $[55,56]$. From the perspective of road supply and demand, we regard road area and bus quantity as the supply items of urban traffic (positive indicator), while urban population as the demand item (negative indicator). This paper measures urban traffic congestion level by dividing traffic supply by demand. The larger the value, the less congestion of urban traffic. The smaller the value, the more serious the urban traffic congestion. As a validity check, this indicator was compared to the urban traffic congestion index published by Amap and the two were found to be highly correlated [57].

Control variables (CTR). In order to avoid the endogenous influence caused by the omission of important explanatory variables, we add a group of control variables that may have an impact on the traffic congestion in Equation (1). It includes: (a) economic activity (ECO). The level of urban economy will directly affect the government's investment in transportation infrastructure. The per capita GDP of the city is used to measure economic activity; (b) science and technology expenditure (STE). This index represents the proportion of government investment in science and technology projects, since the availability of scientific and technical skills may aid the implementation of smart city projects; (c) foreign direct investment (FDI). We use the proportion of FDI in GDP to measure the level of FDI in cities; (d) industrialization (IND). The proportion of the added value of the secondary industry to GDP is used to measure the degree of industrialization of the city, in order to capture the industry structure; (e) human capital level (EDU). The human capital with higher education may manage to learn ICTs faster, and may adapt to the changes of social life brought by modern technology. We use "the number of students in colleges and universities/total urban population" to measure this variable; (f) population density (POP). This paper uses "total population / urban area" to measure this 
quantity; (g) public transportation (BUS). Public transportation can serve a large proportion of public travel, which can alleviate the current situation of urban congestion. Therefore, we use "total bus and trolley passenger traffic/total urban population" to measure.

The following variables will also be used in the further study: (a) innovation effect (INN). The data from "China's urban and industrial innovation report" is used to measure the degree of urban innovation and development; (b) public travel demand (EMP). The public travel demand is largely derived from the morning and evening commutes of urban employees, and traffic congestion also funnels into the morning and evening peak period. Therefore, the total working population is used to measure public travel demand; (c) technical effect (TECH). The technology effect is generally reflected by the number of broadband users.

Panel data on 187 Chinese prefecture level cities in 2008-2017 is utilized in this study. Compared to the county and township levels, more complete and reliable datasets are available for prefecture level cities. Since China's prefecture level cities are highly urbanized, a large number of smart city pilots are also concentrated at this level. Research data are collected from China Urban Statistical Yearbook, the China Urban and Industrial Innovation Report, and relevant regional statistical bulletins. Table 1 presents the descriptive statistics of each variable.

Table 1. Summary statistics of the main variables for 187 prefecture level cities, 2008-2017.

\begin{tabular}{ccccccc}
\hline Variable & Units & Number & Mean & Standard Deviation & Minimum & Maximum \\
\hline TP & $/$ & 1868 & $22,781.38$ & $74,785.43$ & 78.03 & $1,132,569.11$ \\
ECO & Yuan & 1870 & $59,636.6$ & $49,872.75$ & 4410.09 & $506,301.3$ \\
FDI & $\%$ & 1862 & 0.39 & 0.45 & 0 & 5.62 \\
STE & $\%$ & 1870 & 1.72 & 1.69 & 0.01 & 23.12 \\
IND & $\%$ & 1870 & 50.01 & 11.89 & 9.74 & 87.97 \\
EDU & $\%$ & 1865 & 4.70 & 4.09 & 0 & 24.09 \\
POP & $/ \mathrm{km} 2$ & 1870 & 1024 & 945 & 13 & 11,449 \\
BUS & $\%$ ooo & 1869 & 119.48 & 113.57 & 1.96 & 1591.57 \\
INN & $/$ & 1870 & 12.48 & 55.66 & 0.01 & 1061.37 \\
EMP & 10,000 people & 1870 & 38.77 & 84.49 & 1.14 & 923.3 \\
TECH & $\%$ & 1869 & 2.32 & 1.89 & 0.09 & 12.14 \\
\hline
\end{tabular}

\section{Empirical Results}

\subsection{Preliminary Analysis}

The results from DID estimating Equation (1) of a smart city pilot and urban traffic congestion are presented in Table 2. Column (1) is the benchmark test without adding any control variables after controlling for the city fixed effect and the year fixed effect. The estimation coefficient of treat $\times$ post is significantly positive at the level of $1 \%$, which indicates that the traffic congestion improvement in the pilot smart cities is significantly better than in the non-pilot cities. In order to further eliminate the endogenous impact of missing variables, control variables are added in column (2), and the estimated coefficient of treat $\times$ post is significantly reduced, but the result is still significantly positive $\left(\beta_{1}=8185.145, p<0.05\right)$, which indicates that smart city construction significantly reduces traffic congestion. Thus, $\mathrm{H} 1$ is verified.

Column 3 in Table 2 presents the results of the DID estimation with a sample generated through Propensity Score Matching (see Section 4.2 below). Column 4 shows the results that include dynamic effects (see Section 4.4 below). 
Table 2. Analysis Result.

\begin{tabular}{|c|c|c|c|c|}
\hline Variable & (1) & (2) & (3) & (4) \\
\hline Treat $\times$ Post & $\begin{array}{c}20,758.97^{* * *} \\
(7249.77)\end{array}$ & $\begin{array}{l}8185.15^{* *} \\
(2693.60)\end{array}$ & $\begin{array}{c}6171.89 * * * \\
(2151.50)\end{array}$ & \\
\hline Treat $\times$ Post 2012 & & & & $\begin{array}{c}1896.05 \\
(1047.98)\end{array}$ \\
\hline Treat $\times$ Post 2013 & & & & $\begin{array}{c}1878.63 \\
(1311.29)\end{array}$ \\
\hline Treat $\times$ Post2014 & & & & $\begin{array}{l}4214.61^{* * *} \\
(1733.03)\end{array}$ \\
\hline Treat $\times$ Post 2015 & & & & $\begin{array}{l}6249.28 * * \\
(2883.74)\end{array}$ \\
\hline Treat $\times$ Post2016 & & & & $\begin{array}{l}5768.90^{* * *} \\
(2568.24)\end{array}$ \\
\hline Treat $\times$ Post 2017 & & & & $\begin{array}{l}6720.25 * * \\
(3090.22)\end{array}$ \\
\hline ECO & & $\begin{array}{l}0.56^{* *} \\
(0.28)\end{array}$ & & $\begin{array}{l}0.16^{* * *} \\
(0.04)\end{array}$ \\
\hline FDI & & $\begin{array}{c}1705.17 \\
(1422.60)\end{array}$ & & $\begin{array}{c}-533.14 \\
(1073.91)\end{array}$ \\
\hline STE & & $\begin{array}{l}-1028.96 \\
(1083.25)\end{array}$ & & $\begin{array}{c}319.21 \\
(408.80)\end{array}$ \\
\hline IND & & $\begin{array}{l}-229.11 \\
(162.30)\end{array}$ & & $\begin{array}{l}-41.22 \\
(55.45)\end{array}$ \\
\hline EDU & & $\begin{array}{c}-69.35 \\
(720.12)\end{array}$ & & $\begin{array}{l}812.59 * * \\
(403.40)\end{array}$ \\
\hline POP & & $\begin{array}{l}3.16 \\
(2.10)\end{array}$ & & $\begin{array}{c}0.76 \\
(1.17)\end{array}$ \\
\hline BUS & & $\begin{array}{l}-13.92 \\
(13.83)\end{array}$ & & $\begin{array}{c}4.41 \\
(5.37)\end{array}$ \\
\hline City fixed effect & Yes & Yes & Yes & Yes \\
\hline Year fixed effect & Yes & Yes & Yes & Yes \\
\hline R-square & $7.41 \%$ & $53.58 \%$ & $10.28 \%$ & $44.79 \%$ \\
\hline Number of observations & 1868 & 1854 & 1328 & 1327 \\
\hline Number of groups & 187 & 187 & 133 & 133 \\
\hline
\end{tabular}

Note: Cluster standard errors in parentheses; ${ }^{*}, * *$, and ${ }^{* * *}$ represent $10 \%, 5 \%$, and $1 \%$ significant levels, respectively.

\subsection{PSM-DID Analysis}

Ensuring the accuracy of the above model estimation, we need to assume that the government's decision (on which cities to execute a smart city policy) is based on complete randomness. Namely, there should be no selection bias between the treatment group and the control group in the overall characteristics of the city. If the government chooses the more developed areas to become the pilot smart cities, it will inevitably overestimate the improvement effect on traffic congestion of smart cities since the degree of informatization and overall development may make smart city programs easier to implement.

To further test the accuracy of the estimation in the context of possible selection bias, the propensity score matching (PSM) technique is used. The implementation of PSM requires a set of variables that are unaffected by treatment, which should be included in the matching model. As indicators of general urban development, we choose economic level (ECO), science and technology expenditure (STE), foreign direct investment (FDI), industrialization level (IND), human capital level (EDU), population size (POP), public transportation (BUS), and innovation effect (INN). Together, these variables indicate whether pilot selection depended on urban economic development, industrial structure, public finance, the city's science and technology investment, population scale, traffic demand, etc. Through PSM, we can select the control group matching the situation of the treatment group before the smart city policy appeared on the stage, reducing the endogeneity problem caused by non-random selection [58]. 
The pairwise comparisons in Table 3 illustrate why we undertake a matching approach when comparing these two groups. Column 1 presents the bias in the variable means before the matching process. As expected, the pilot smart cities have higher indicators on most variables, such as economic level and science and technology expenditures, except for industrialization where the two groups are roughly comparable. Outperformance on these indicators lays a strong foundation to promote the implementation of smart city in the pilot cities. Thus, directly comparing unmatched cities is unlikely to provide an accurate estimate of the impact of the smart cities on traffic congestion. To counter this, we implement a matching procedure that relies on nearest neighbor matching. As shown in column 2, the matching process reduces the standard bias of most variables to less than $10 \%$ after matching. The results of $t$-test do not reject the null hypothesis that there is no systematic difference between the treated and control group.

Table 3. Propensity Score Matching Diagnostics.

\begin{tabular}{|c|c|c|c|c|c|}
\hline \multirow[b]{2}{*}{ Variable } & \multirow[b]{2}{*}{ Sample } & \multicolumn{2}{|c|}{ Pairwise Comparisons } & \multicolumn{2}{|c|}{ Logistic Regression } \\
\hline & & $\begin{array}{c}\text { (1) } \\
\text { \%bias }\end{array}$ & $\begin{array}{c}\text { (2) } \\
\text { T-diff }\end{array}$ & (3) & (4) \\
\hline \multirow[t]{2}{*}{$\mathrm{ECO}$} & Pre-match & 93.3 & $6.71^{* * *}$ & $\begin{array}{c}0.000011 \\
\left(8.76 \times 10^{-6}\right)\end{array}$ & \multirow[b]{2}{*}{$\begin{array}{c}0.0000103 \\
\left(8.99 \times 10^{-6}\right)\end{array}$} \\
\hline & Post-match & 0.2 & 0.01 & & \\
\hline \multirow[t]{2}{*}{ STE } & Pre-match & 103.3 & $7.27^{* * *}$ & $\begin{array}{l}0.38 * \\
(0.21)\end{array}$ & \multirow[b]{2}{*}{$\begin{array}{c}0.33 \\
(0.22)\end{array}$} \\
\hline & Post-match & -21.8 & -1.07 & & \\
\hline \multirow[t]{2}{*}{ FDI } & Pre-match & 63.2 & $4.01^{* * *}$ & $\begin{array}{c}0.52 \\
(0.54)\end{array}$ & \multirow[b]{2}{*}{$\begin{array}{c}0.40 \\
(0.55)\end{array}$} \\
\hline & Post-match & -29.2 & -1.14 & & \\
\hline \multirow[t]{2}{*}{ IND } & Pre-match & -4.2 & 5.61 & $\begin{array}{c}0.0270702 \\
(0.0256062)\end{array}$ & \multirow[b]{2}{*}{$\begin{array}{c}0.0111385 \\
(0.0274755)\end{array}$} \\
\hline & Post-match & -21.4 & 0.11 & & \\
\hline \multirow[t]{2}{*}{ EDU } & Pre-match & 83.7 & $5.76^{* * *}$ & $\begin{array}{l}0.15^{* *} \\
(0.07)\end{array}$ & \multirow[b]{2}{*}{$\begin{array}{c}0.11 \\
(0.08)\end{array}$} \\
\hline & Post-match & 29.5 & 1.43 & & \\
\hline \multirow[t]{2}{*}{ POP } & Pre-match & 52.3 & $3.52^{* * *}$ & $\begin{array}{c}2.40 \\
(2.07)\end{array}$ & \multirow[b]{2}{*}{$\begin{array}{c}2.22 \\
(2.02)\end{array}$} \\
\hline & Post-match & 18.9 & 0.77 & & \\
\hline \multirow[t]{2}{*}{ BUS } & Pre-match & 81.8 & $5.61^{* * *}$ & $\begin{array}{c}-0.002301 \\
(0.0030153)\end{array}$ & \multirow[b]{2}{*}{$\begin{array}{l}-0.0018178 \\
(0.0030399)\end{array}$} \\
\hline & Post-match & 2.6 & 0.11 & & \\
\hline \multirow[t]{2}{*}{ INN } & Pre-match & 60.3 & $4.85^{* * *}$ & $\begin{array}{c}0.1140133 \text { ** } \\
(0.0492923)\end{array}$ & \multirow[b]{2}{*}{$\begin{array}{c}0.0666959 \\
(0.0560165)\end{array}$} \\
\hline & Post-match & 3.0 & 1.27 & & \\
\hline \multirow[t]{2}{*}{ Tech } & Pre-match & 51.1 & $3.53^{* * *}$ & $\begin{array}{l}-0.37 \\
(0.41)\end{array}$ & \multirow[b]{2}{*}{$\begin{array}{c}-0.2135741 \\
(0.4584026)\end{array}$} \\
\hline & Post-match & 14.3 & 0.77 & & \\
\hline
\end{tabular}

Note: Cluster standard errors in parentheses; ${ }^{* * *}$, and ${ }^{* * *}$ represent $10 \%, 5 \%$, and $1 \%$ significant levels, respectively.

Columns 3 and 4 present the results of two logistic regressions (pre- and post-match) with a binary dependent variable indicating whether or not a particular city is pilot smart city. Models are 
estimated on a cross section of 58 pilot cities (treatment) and 129 non-pilot cities (control) with nonmissing data for all of the variables included in the specification. The pre-match model (column 3 ) shows that several variables (STE, EDU, INN) significantly predicted that cities will be selected as pilots. However, in the post-match model (column 4), none of the factors have statistically significant differences after matching, and the size of estimated coefficients has declined. Thus, PSM reduces the differences between the treated and control group, ensuring that the parallel trend assumption is satisfied [59]. The result of the matching process is a treatment group consisting of 37 pilot cities and a control group of 96 non-pilot cities.

The third column in Table 2 presents the results of the DID estimation using the matched sample. Note that there is no need for additional control variables since the treated and control cities are already matched, nonparametrically, on all of the relevant observable characteristics. It can be seen from the regression results that after reducing the endogeneity caused by non-random selection of the treatment group, $\beta_{1}$ is still significantly positive, which shows that smart city construction can indeed ease the traffic congestion issue and improve the overall traffic level of the city. The results are qualitatively similar to column (2) of Table 2.

\subsection{Mechanism Analysis}

The previous test provided support the hypothesis that a smart city strategy does give impetus to the improvement of traffic congestion. However, we also need to explore how smart cities work and question, what is the realization path? As discussed earlier, one of the pathways may be through the innovation and technology promotion that smart city programs bring to the city.

We use the bootstrap program to estimate the intermediary effect of innovation and technology, respectively, using 1000 Monte Carlo replications [60]. The results show that the deviation correction confidence interval of innovation effect at $95 \%$ level is [965.25, 4423.22], which does not contain 0 , so there is intermediary effect; the deviation correction confidence interval of technology effect at $95 \%$ level is [1638.89, 3909.03], which does not contain 0, so there is an intermediary effect. The above mechanism analysis suggests that the construction of smart city gives full play to the policy dividend. Through the innovation effect and technological change, smart cities ultimately ease urban traffic congestion. $\mathrm{H} 2 \mathrm{a}$ and $\mathrm{H} 2 \mathrm{~b}$ verified.

\subsection{Dynamic Effect Analysis}

The construction of a smart city is a long-term and complex systemic project, so its effect may be gradually enhanced with the passage of time. Our paper constructs an estimating model as shown in Equation (2), and tests the dynamic effect of smart city construction on urban traffic congestion. PostK indicates that in year $K$, the value is 1 ; otherwise, it is 0 . The estimation coefficient $\beta_{\mathrm{k}}$ measures the dynamic effect of smart city pilot on urban traffic congestion.

$$
\mathrm{TP}_{\mathrm{it}}=\beta_{0}+\sum_{\mathrm{K}=2012}^{2017} \beta_{1 \mathrm{k}} \operatorname{Treat}_{\mathrm{i}} \times \operatorname{PostK}_{\mathrm{t}}+\gamma \mathrm{Ctr}_{\mathrm{it}}+\eta_{\mathrm{i}}+v_{\mathrm{t}}+\varepsilon_{\mathrm{it}}
$$

According to the regression results in column (4) of Table 2, the estimated coefficients of Treat $\times$ Post2012 and Treat $\times$ Post2013 failed to pass the significance test, while the estimated coefficients of Treat $\times$ Post2014, Treat $\times$ Post2015, Treat $\times$ Post2016 and Treat $\times$ Post2017 gradually increased, and all passed the $5 \%$ significance test.

It can be seen that the capacity of smart city pilots to improve urban traffic congestion does not manifest immediately at the beginning of policy implementation. However, the improvement effect is gradually enhanced in the following years; thus, verifying H3. As our dataset extends only up to 2017, we cannot observe the dynamic impact of smart city pilot on traffic congestion improvement after 2017. However, the regression results show, to some extent, that the policy effect of smart city pilots is long-term, and gradually increases as time goes on. 


\subsection{Heterogeneity Analysis of Urban Characteristics}

The implementation of smart city policies in the field of transportation requires certain human capital, as well as the support and promotion of public travel demand and traditional public transport infrastructure construction. Only in this way can we give full play to the role of smart cities in improving traffic congestion. Therefore, the analysis of these urban development characteristics can directly provide guidance for policy design.

Accordingly, we estimate the impact of human capital, public travel demand and public transportation level on urban traffic congestion in smart city construction, in the following equation:

$$
\mathrm{TP}_{\mathrm{it}}=\beta_{0}+\beta_{2} \text { Treat }_{\mathrm{i}} \times \text { Post }_{\mathrm{t}} \times \mathrm{F}_{\mathrm{it}}+\gamma \mathrm{Ctr}_{\mathrm{it}}+\eta_{\mathrm{i}}+v_{\mathrm{t}}+\varepsilon_{\mathrm{it}}
$$

In Equation (3), $F$ represents the characteristic variables, such as human capital (EDU), public travel demand (EMP), and public transport level (BUS).

The heterogeneity analysis results in Table 4 show that there are obvious differences in the construction of smart cities with different urban characteristics and resource endowments; thus, verifying the $\mathrm{H} 4 \mathrm{a}, \mathrm{H} 4 \mathrm{~b}$, and $\mathrm{H} 4 \mathrm{c}$ in our paper.

Table 4. Heterogeneity Analysis Results.

\begin{tabular}{cccc}
\hline Variable & $\mathbf{( 1 )}$ & $\mathbf{( 2 )}$ & (3) \\
\hline Treat $\times$ Post $\times$ EDU & $9.29^{* * *}$ & & \\
Treat $\times$ Post $\times$ EMP & $(3.21)$ & $197.87^{* * * *}$ & \\
Treat $\times$ Post $\times$ BUS & & $(35.56)$ & $48.92^{* * *}$ \\
Control Variables & & & $(12.73)$ \\
City fixed effect & Yes & Yes & Yes \\
Year fixed effect & Yes & Yes & Yes \\
R-square & Yes & Yes & Yes \\
Number of observations & $44.03^{*}$ & $50.71 \%$ & $46.94 \%$ \\
Number of groups & 1327 & 1328 & 1327 \\
\hline
\end{tabular}

Note: Cluster standard errors in parentheses; ${ }^{* * *}$ represents $1 \%$ significant level.

The first column of Table 4 examines the impact of smart city construction on traffic congestion under different urban human capital levels. The estimated coefficient of Treat $\times$ Post $\times$ EDU is significantly positive, indicating that the higher the education level of urban population, the more significant the traffic improvement effect of smart city construction. The foundation of smart city is modern information technology, but the acquisition and application of these technologies necessitate certain human capital endowments. It is relatively easy for a highly educated labor force to learn and apply the new generation of information technology, so as to better carry out the construction of smart city. In addition, in cities with a high level of public education, the public's compliance with traffic rules and maintenance of traffic order also helps avoid the urban traffic congestion caused by accidents.

The second column examines the impact of smart city construction on urban traffic congestion level under different urban public travel demand. The coefficient of Treat $\times$ Post $\times$ EMP is positive at the significance level of $1 \%$, indicating that the greater the public travel demand, the greater the traffic improvement effect of the smart city. Public travel demand reflects the demand degree of urban population for road traffic. The traffic congestion at the morning and evening peak is mostly caused by commuters traveling to and from their homes and workplaces. Therefore, for cities with a large working population, the government urgently needs to manage urban traffic through smart information technology solutions.

The third column examines the impact of smart city construction on urban traffic congestion under changes in the availability of urban public transportation. The coefficient of Treat $\times$ Post $\times$ BUS is significantly positive, suggesting that the higher the supply of public transportation, the better the effect 
of smart city on traffic congestion. For cities with better public transport infrastructure, the addition of ICTs and other technologies can greatly improve the process of public ticket purchase and check-in, the arrival times of buses and subway trains can be checked in real time, and the transportation operations department can make optimum scheduling through intelligent means to alleviate local congestion and enhance the city's commuting ability.

\subsection{Geographical Heterogeneity Analysis}

Due to the vast scale of China, there are great differences among cities. In addition to the added control variables, local governments-while implementing the smart city construction plan-will also combine the resource advantages, political advantages, and cultural advantages brought by their geographical location to choose the policy tendency and core industry layout of smart city construction. This will, to a certain extent, affect the effect of smart city measures in alleviating urban traffic congestion. Chinese cities gradually show obvious common differences according to geographical location and local culture in the long-term urbanization development process. The Chinese government and researchers habitually divide the Chinese cities into three parts: the East, the Middle, and the West. Due to the geographical, cultural, economic, and other reasons, the three parts have formed different paths and characteristics in the process of urbanization. Therefore, according to this classification method based on geographical location, we carry out DID analysis, and find that it is more suitable for different types of cities.

For the eastern region, relying on the coastal advantages, the cities have played a huge role in the opening up, and have successively formed the urban agglomerations represented by Beijing-Tianjin-Hebei region, Yangtze River Delta, Guangdong-Hong Kong-Macao Greater Bay Area, etc. Meanwhile, the eastern cities are densely populated and the industrial innovation speed is rapid, which have become the core area to drive the sustained and rapid growth of the national economy. For the middle region, it mainly forms the grain production base and the key areas of energy and raw material supply. Although the development of central cities and urban agglomerations in the middle region lag behind that in the eastern, the urban structure system is gradually improved. With the rapid development of transportation infrastructure and control system, many cities have become national transportation hubs, connecting eastern, middle and western cities in China. For the western region, although the urbanization rate has been gradually increased through the implementation of the western development strategy, it still lags behind the eastern and central regions. There are also serious urban-rural differences in western cities. Moreover, the development gap between the western cities is quite large, and the regional core cities, such as Chengdu and Chongqing, are obviously superior to the surrounding cities in economy, public service, and social governance. In addition, the ethnic diversity of western cities also limits the development of social economy, to a certain extent.

In order to test whether the urban development differences brought about by different geographical locations have an impact on the smart city policy in terms of traffic governance, we use Equation (1) to conduct a double difference analysis, according to the eastern, middle, and western cities, and the results are shown in Table 5.

Table 5. Regression results based on geographical location.

\begin{tabular}{cccc}
\hline Variable & East & Middle & West \\
\hline Treat $\times$ Post & $11,353.41^{* *}$ & $4191.57^{* *}$ & $10,261.04$ \\
Control Variables & $(4865.92)$ & $(1972.54)$ & $(5619.64)$ \\
City fixed effect & Yes & Yes & Yes \\
Year fixed effect & Yes & Yes & Yes \\
R-square & Yes & Yes & Yes \\
Number of observations & $56.80 \%$ & $55.78 \%$ & $39.57 \%$ \\
Number of groups & 917 & 490 & 447 \\
\hline Note: Cluster standard errors in parentheses; ${ }^{* *}$ represents 5\% significant level.
\end{tabular}

Note: Cluster standard errors in parentheses; ${ }^{* *}$ represents $5 \%$ significant level. 
The results show that after the implementation of smart city policy in the eastern and middle regions, the urban traffic congestion has improved significantly, but the improvement effect of western cities is not obvious. Moreover, the construction of smart cities in the eastern region has a stronger traffic congestion alleviating effect than that in the middle region. Combined with the practice of three regions, it is found that the eastern cities have always been the core area of China's social and economic development due to their open cultural atmosphere and coastal advantages, providing sufficient human and financial support for the promotion and implementation of the smart city policy; thus, achieving obvious governance effect. Specifically, relying on the urban transportation big data center, Beijing optimizes the signal timing with big data, realizes the construction of green belt road, and improves the overall traffic speed of the road network. Thanks to the strong technical support of the Internet industry, such as Alibaba, Hangzhou took the lead in proposing the urban brain system, which takes the traffic field as a breakthrough, senses the dynamic changes of urban traffic through various sensors, and realizes the intelligent calculation of traffic accident disposal strategies and the number of police. Although the cities in the middle region are not dominated by science and technology innovation and information development policies, they are close to the eastern cities, greatly affected by the diffusion of policy innovation. In addition, they are the transportation hub linked to the east and west of China, which have complete transportation infrastructure. Therefore, the pilot cities represented by the urban agglomerations in the middle reaches of the Yangtze River and the Central Plains have made great achievements in the construction of smart cities. However, the construction of smart cities in the western region has not had a positive impact on the alleviation of traffic congestion. Firstly, although some cities in the western region have been included in the national list of pilot construction of smart cities, local governments have not issued specific construction plans and programs in time, which makes the policy effect difficult to reflect in the short term. Xi'an, Chongqing, and other regional core cities, as representatives, have successively launched the overall plan of smart city construction in 2015. Secondly, although the western region is actively learning from the construction of smart cities in the eastern region, its urban infrastructure is difficult to meet the construction needs. The unbalanced and inadequate development of the cities in the province is obvious. It is difficult to integrate the information system of western cities, which hinders the collection, sharing, analysis, and application of data to some extent. Thirdly, the western region actively explores its own potential and finds the development path suitable for the current situation. Thus, some cities have not fully carried out intelligent construction in the field of transportation. For example, Chengdu focuses on the development of digital economy, playing the node city function of "Belt and Road Initiative". Due to the transfer of financial resources and the focus of research and development, Chengdu's construction of transportation intelligent decision-making system is far behind Hangzhou, Beijing, and other eastern cities. Therefore, the traffic congestion alleviating effect of Chengdu through a smart city is not significant.

\section{Discussion}

Through the empirical analysis, it can be found that the construction of a smart city significantly alleviates urban traffic congestion after overcoming the estimation deviation, and mainly drives the solution of traffic problems through the application of information technology and innovative development. These results are similar to recent studies. Through summarizing the applications of intelligent devices in the field of urban traffic, Toh points out that congestion, accidents, exhaust emissions, and other problems will be solved under the construction of smart city [61]. Vakula deeply analyzed the information development of the public transport system and proposed the positive role of an intelligent public transport system in ameliorating congestion [62]. Meanwhile, the research results also echo a good deal of literature in the introduction and hypothesis sections, and support the theoretical analysis of that literature from an empirical level.

It is essential to consider a few potential limitations in the present study. One limitation is the data limitations. It is difficult to characterize the level of traffic congestion through direct variables, such as 
peak average speed, average congestion time, etc. Although we draw lessons from previous studies and construct the urban traffic congestion level through key variables, the explanation of urban traffic congestion status is still limited. In addition, Bauza has proposed to detect the travel behavior of the cars in real time through big data modeling to provide prediction and measurement of the possibility of traffic congestion [63]. However, for our study, it is difficult to trace the traffic situation before the construction of smart city, so it is impossible to obtain the early level of traffic congestion through modeling. With the development of the third-party assessment organization based on the field of urban traffic, it may provide more accurate urban traffic data for related study.

The second limitation of our study comes from the structure of urban road network. In the process of urbanization, in addition to the growing population and vehicles, the inherent urban road network structure will also cause traffic congestion. However, this variable is difficult to control reasonably in the study. In the Chinese cities selected, the road network of each city is very complex. Most cities represented by Beijing and $\mathrm{Xi}^{\prime}$ an continue the ancient road model of China. The internal road structure is mainly formed by the horizontal and vertical crossing grids, and the circular radial road network spreads outward. In Chongqing, Guizhou and other mountainous cities, multi group road network structure is often used for road layout. Moreover, some small and medium-sized cities mainly adopt the strip road network structure because of river channel, and gradually connect the surrounding cities during urbanization, forming a mixed road network structure of strip and multi group road network. Although it is of great practical significance to analyze the improvement of traffic congestion in smart city construction based on the road network structure, it is difficult to accurately classify the urban road network, so we does not specifically analyze the heterogeneity based on the road network structure.

\section{Conclusions and Implications}

As a new type of city development strategy relying on information technology, smart city construction promises to reform the traditional urban organization and management model, so as to promote the effective allocation of data and resources and solve the problems of urbanization. However, the current literature has not effectively studied the traffic amelioration impacts of the smart city. To remedy this gap in the literature, this paper used panel data from 187 prefecture-level cities in China from 2008 to 2017 to verify whether smart city construction can alleviate urban traffic congestion by using the difference-in-difference method.

The results show that the construction of smart cities significantly reduces the level of urban traffic congestion and improves the quality of urban traffic; the effect remains valid after a robustness test based on PSM-DID. The mechanism verification shows that smart city construction not only regards information technology as a way to manage traffic problems, but also reduces urban traffic congestion through overall urban innovation. Additionally, the improvement effect of smart city construction on transportation accelerates over time, which also shows that the effect of smart city construction cannot be seen overnight, but requires continuous government investment in construction. Heterogeneity research shows that the level of human capital, labor population, and public transportation can significantly enhance the improvement effect of smart cities on traffic congestion.

The research conclusions of this paper have important practical significance for supporting the construction of smart cities and alleviating urban traffic congestion. First, as an important "policy experiment" in China, the smart city pilot provides a solution for the increasingly serious problems of urbanization in the rapid development of cities. In view of the positive improvement effect of smart cities on urban transportation, the government should make full use of this "policy pilot," spare no effort to further promote the construction of smart cities. In addition, the government may further explore its wide use in other public services and urban governance, promoting the resolution of other social problems, such as environmental pollution, resources shortages, and urban poverty.

Second, the government may seek to improve the effect of urban governance through technological revolution, transform urban governance through innovation, and give full play to the policy dividends of smart city construction. Information technologies such as IOT, big data, cloud computing, and 
artificial intelligence are the technological foundations of smart city construction. Strengthening technological research and development has important strategic advantages. In addition, as an innovation policy, smart city also requires the overall innovation of urban governance and development models to provide a facilitative environment for innovation. From the perspective of traffic governance, building a traffic flow data big data platform can comprehensively depict the real-time congestion of urban roads, and provide a scientific basis for intelligent decision-making. Meanwhile, the wide application of technological innovation products such as Internet of Vehicles and driverless vehicles can not only emphasize the convenience and low cost of travel services, but also reduce energy consumption and mitigate congestion. On the other hand, government transportation agencies need to cooperate with technological changes to establish innovative management framework, establish a smart transportation group or information group, introduce staff with technical thinking and innovative ideas, and (orderly and rationally) transition traditional transportation management methods to new transportation governance mode.

Thirdly, as a complex systemic project, the construction of a smart city requires not only long-term investment, but also targeted construction of related fields according to the development characteristics and resource endowments of each city. Due to the huge difference in various aspects of economic and social development among cities, the requirement of "one size fits all" for all cities to comprehensively promote the smart city construction is unrealistic and inefficient. In terms of traffic congestion, for cities with small urban population density and mild traffic congestion, vigorously developing smart transportation will make the cost exceed the benefit. For congested cities where traditional traffic governance has gradually become inefficient, the development of smart transformations focusing on public transportation and road infrastructure can fully realize the potential of smart cities to maximize governance efficiency.

Author Contributions: Conceptualization, Y.G.; Methodology, Z.T.; Software, Y.G.; Validation, Y.G. and Z.T.; Formal Analysis, Y.G.; Investigation, Z.T.; Data Curation, Y.G. and J.G.; Writing-Original Draft Preparation, Y.G. and J.G.; Writing-Review and Editing, Y.G.; Supervision, Z.T.; Project Administration, Z.T.; Funding Acquisition, Z.T. All authors have read and agreed to the published version of the manuscript.

Funding: This research was funded by the National Social Science Foundation of China (NSFC) grant (grant number: 18VSJ057).

Conflicts of Interest: The authors declare no conflict of interest.

\section{References}

1. Accetturo, A. Agglomeration and growth: The effects of commuting costs. Pap. Reg. Sci. 2010, 89, 173-190. [CrossRef]

2. 2018 Revision of World Urbanization Prospects. Available online: https://www.un.org/development/desa/ publications/2018-revision-of-world-urbanization-prospects.html (accessed on 27 February 2020).

3. Zhang, L. Special Issue: Urbanization in China: Processes and Policies||The Right to the Entrepreneurial City in Reform-Era China. China Rev. 2010, 10, 129-155. [CrossRef]

4. National Bureau of Statistics. Available online: http://www.stats.gov.cn/tjsj/ndsj/ (accessed on 12 November 2019).

5. Beijing Transportation Development Annual Report 2018. Available online: http://www.bjtrc.org.cn/list/ index/cid/7.html (accessed on 12 November 2019).

6. INRIX Global Traffic Scorecard. Available online: https://trid.trb.org/view/1456836 (accessed on 27 February 2020).

7. Arnott, R. Congestion tolling with agglomeration externalities. J. Urban Econ. 2007, 62, 203. [CrossRef]

8. Chin, A.T.H. Containing air pollution and traffic congestion: Transport policy and the environment in Singapore. Atmos. Environ. 1996, 30, 801. [CrossRef]

9. Hymel, K. Does traffic congestion reduce employment growth? J. Urban Econ. 2009, 65, 135. [CrossRef]

10. Aftabuzzaman, M.; Currie, G.; Sarvi, M. Exploring the underlying dimensions of elements affecting traffic congestion relief impact of transit. Cities 2011, 28, 36-44. [CrossRef] 
11. Ewing, R.; Tian, G.; Lyons, T. Does compact development increase or reduce traffic congestion? Cities 2018, 72, 94-101. [CrossRef]

12. Wang, F.Y.; Ye, C.M.; Li, Y. Study on Reasons and Countermeasures of Traffic Congestion of Urban Road Based on the Queuing Models. In Proceedings of the 2013 International Conference on Computational and Information Sciences, Hubei, China, 21-23 June 2013.

13. Zhao, L.; Lai, Y.-C.; Park, K.; Ye, N. Onset of traffic congestion in complex networks. Phys. Rev. E Stat. Nonlinear Soft Matter Phys. 2005, 71, 026125. [CrossRef]

14. Han, F.; Xie, R.; Lai, M.Y. Traffic density, congestion externalities, and urbanization in China. Spat. Econ. Anal. 2018, 13, 400-421. [CrossRef]

15. Brady, M.E. Dynamic stability, traffic equilibrium and the law of peak-hour expressway congestion. Transp. Res. Part B Methodol. 1993, 27, 229-236. [CrossRef]

16. Henderson, J.V.; Roberts, M.; Storeygard, A. Is Urbanization in Sub-Saharan Africa Different? Social Science Electronic Publishing: New York, NY, USA, 2013.

17. Appio, F.P.; Lima, M.; Paroutis, S. Understanding Smart Cities: Innovation ecosystems, technological advancements, and societal challenges. Technol. Forecast. Soc. Chang. 2019, 142, 1-14. [CrossRef]

18. Vanolo, A. Smartmentality: The Smart City as Disciplinary Strategy. Urban Stud. 2014, 51, 883-898. [CrossRef]

19. Bhati, A.; Hansen, M.; Chan, C.M. Energy conservation through smart homes in a smart city: A lesson for Singapore households. Energy Policy 2017, 104, 230-239. [CrossRef]

20. Zawieska, J.; Pieriegud, J. Smart city as a tool for sustainable mobility and transport decarbonisation. Transp. Policy 2018, 63, 39-50. [CrossRef]

21. Behrendt, F. Cycling the Smart and Sustainable City: Analyzing EC Policy Documents on Internet of Things, Mobility and Transport, and Smart Cities. Sustainability 2019, 11, 763. [CrossRef]

22. Peng, G.C.A.; Nunes, M.B.; Zheng, L. Impacts of low citizen awareness and usage in smart city services: The case of London's smart parking system. Inf. Syst. E-Bus. Manag. 2016, 15, 1-32. [CrossRef]

23. Paroutis, S.; Bennett, M.; Heracleous, L. A strategic view on smart city technology: The case of IBM Smarter Cities during a recession. Technol. Forecast. Soc. Chang. 2014, 89, 262-272. [CrossRef]

24. Angelidou, M. Smart city policies: A spatial approach. Cities 2014, 41, S3-S11. [CrossRef]

25. Batty, M.; Axhausen, K.W.; Giannotti, F.; Pozdnoukhov, A.; Bazzani, A.; Wachowicz, M.; Ouzounis, G.; Portugali, Y. Smart cities of the future. Eur. Phys. J. Spec. Top. 2012, 214, 481-518. [CrossRef]

26. Nam, T.; Pardo, T.A. Smart city as urban innovation: Focusing on management, policy, and context. In Proceedings of the ICEGOV 2011 5th International Conference on Theory and Practice of Electronic Governance, Tallinn, Estonia, 26-28 September 2011.

27. Harrison, C.; Eckman, B.; Hamilton, R.; Hartswick, P.; Kalagnanam, J.; Paraszczak, J.; Williams, P. Foundations for Smarter Cities. IBM J. Res. Dev. 2010, 54. [CrossRef]

28. Angelidou, M. Smart cities: A conjuncture of four forces. Cities 2015, 47, 95-106. [CrossRef]

29. Kogan, N.; Lee, K.J. Exploratory Research on the Success Factors and Challenges of Smart City Projects. Asia Pac. J. Inf. Syst. 2014, 24, 141-189. [CrossRef]

30. Caragliu, A.; Del Bo, C.; Nijkamp, P. Smart Cities in Europe. J. Urban Technol. 2011, 18, 65-82. [CrossRef]

31. Biswas, S.P.; Roy, P.; Mukherjee, N.P.A.; Dey, N. Intelligent Traffic Monitoring System. In Proceedings of the International Conference on Computer and Communication Technologies-IC3T, Hyderabad, Telangana, 24-26 July 2015; pp. 535-545.

32. Flötteröd, G. Intelligent traffic systems. J. Magn. Reson. Imaging 2010, 13, 729-737. [CrossRef]

33. Taylor, M.A.P.; Woolley, J.E.; Zito, R. Integration of the global positioning system and geographical information systems for traffic congestion studies. Transp. Res. Part C 2000, 8, 257-285. [CrossRef]

34. Bangerter, B.; Talwar, S.; Arefi, R.; Stewart, K. Networks and Devices for the 5G Era. IEEE Commun. Mag. 2014, 52, 90-96. [CrossRef]

35. Liu, B.; Khorashadi, B.; Ghosal, D.; Chuah, C.-N.; Zhang, H.M. Analysis of the information storage capability of VANET for highway and city traffic. Transp. Res. Part C-Emerg. Technol. 2012, 23, 68-84. [CrossRef]

36. Xie, B.; Chen, Y.; Xu, M.; Wang, Y. Mathematical Modeling of Locally Information Storage Capability of VANET for Highway Traffic. In Mechatronics, Robotics and Automation, Pts 1-3; Kim, Y.H., Ed.; Trans Tech Publications Ltd.: Stafa-Zurich, Switzerland, 2013; Volume 373-375, pp. 1914-1919.

37. Meijer, A.; Thaens, M. Urban Technological Innovation: Developing and Testing a Sociotechnical Framework for Studying Smart City Projects. Urban Aff. Rev. 2018, 54, 363-387. [CrossRef] 
38. Dong, C.; Ma, X.; Wang, B.; Sun, X. Effects of prediction feedback in multi-route intelligent traffic systems. Phys. A-Stat. Mech. Appl. 2010, 389, 3274-3281. [CrossRef]

39. Silva, T.H.; Melo, P.O.; Viana, A.C.; Almeida, J.M.; Salles, J.; Loureiro, A.A. Traffic Condition Is More Than Colored Lines on a Map: Characterization of Waze Alerts. In Proceedings of the 5th International Conference on Social Informatics, Kyoto, Japan, 25-27 November 2013; pp. 309-318.

40. Yujuico, E. Considerations in the diffusion of a public traffic app for Metro Manila. J. Transp. Geogr. 2015, 42, 48-56. [CrossRef]

41. Rohunen, A.; Markkula, J.; Heikkila, M.; Heikkila, J. Open Traffic Data for Future Service Innovation Addressing the Privacy Challenges of Driving Data. J. Theor. Appl. Electron. Commer. Res. 2014, 9, 71-89. [CrossRef]

42. Gilmore, J.F.; Elibiary, K.J.; Forbes, H.C. Terminus-A knowledge-based traffic management-system. IVHS J. 1995, 2, 253. [CrossRef]

43. Houston, D.; Luong, T.T.; Boarnet, M.G. Tracking daily travel; Assessing discrepancies between GPS-derived and self-reported travel patterns. Transp. Res. Part C-Emerg. Technol. 2014, 48, 97-108. [CrossRef]

44. Lopez, C.; Ruiz-Benitez, R.; Vargas-Machuca, C. On the Environmental and Social Sustainability of Technological Innovations in Urban Bus Transport: The EU Case. Sustainability 2019, 11, 1413. [CrossRef]

45. Naseer, M.F.; Khan, K.B.; Khaliq, M.S.; Raheel, M. Smart Road-Lights and Auto Traffic-Signal Controller with Emergency Override. In Intelligent Technologies and Applications, Intap 2018; Bajwa, I.S., Kamareddine, F., Costa, A., Eds.; Springer: Singapore, 2019; Volume 932, pp. 526-537.

46. Pattara-atikom, W.; Pongpaibool, P.; Thajchayapong, S. Estimating road traffic congestion using vehicle velocity. In Proceedings of the 2006 6th International Conference on ITS Telecommunications, Chengdu, China, 21-23 June 2006.

47. Younes, M.B.; Boukerche, A. An efficient dynamic traffic light scheduling algorithm considering emergency vehicles for intelligent transportation systems. Wirel. Netw. 2018, 24, 2451-2463. [CrossRef]

48. Huang, S.L.; Chen, C.-W. Theory of urban energetics and mechanisms of urban development. Ecol. Model. 2005, 189, 49-71. [CrossRef]

49. Lucas, R.E., Jr. On the mechanics of economic development. J. Monet. Econ. 1989, 22, 3-42. [CrossRef]

50. Bonney, R.; Phillips, T.B.; Ballard, H.L.; Enck, J.W. Can citizen science enhance public understanding of science? Public Underst. Sci. 2015, 25, 1-14. [CrossRef]

51. Liu, T.; Ceder, A. Analysis of a new public-transport-service concept: Customized bus in China. Transp. Policy 2015, 39, 63-76. [CrossRef]

52. Gschwender, A.; Munizaga, M.; Simonetti, C. Using smart card and GPS data for policy and planning: The case of Transantiago. Res. Transp. Econ. 2016, 59, 242-249. [CrossRef]

53. Guido, G.; Rogano, D.; Vitale, A.; Astarita, V.; Festa, D. Big data for public transportation: A DSS framework. In Proceedings of the 2017 5th IEEE International Conference on Models and Technologies for Intelligent Transportation Systems (MT-ITS), Napoli, Italy, 26-28 June 2017; pp. 872-877.

54. Heckman, J.J.; Ichimura, H.; Todd, P. Matching As An Econometric Evaluation Estimator. Rev. Econ. Stud. 1998, 65, 261-294. [CrossRef]

55. Andreas, W.; Wang, S.; Peter, J. Traffic congestion estimation service exploiting mobile assisted positioning schemes in GSM networks. Procedia Earth Planet. Sci. 2009, 1, 1385-1392. [CrossRef]

56. Botzow, H. Level-of-service concept for evaluating public transport. Transp. Res. Rec. 1974, 519, 73-84.

57. Amap Urban Transportation Analysis Report. Available online: https://report.amap.com/m/dist/\#/reports (accessed on 28 November 2019).

58. Smith, J.A.; Todd, P.E. Does matching overcome LaLonde's critique of nonexperimental estimators? J. Econom. 2005, 125, 305-353. [CrossRef]

59. Lian, J.; Zak, S.H. Controller Design for a Class of Uncertain Systems with Guaranteed Performance. Siam J. Control Optim. 2011, 49, 1239-1261. [CrossRef]

60. Wen, Z.; Marsh, H.W.; Hau, K.T. Structural Equation Models of Latent Interactions: An Appropriate Standardized Solution and Its Scale-Free Properties. Struct. Equ. Model. A Multidiscip. J. 2010, 17, 1-22. [CrossRef]

61. Toh, C.K.; Sanguesa, J.A.; Cano, J.C.; Martinez, F.J. Advances in smart roads for future smart cities. Proc. R. Soc. A-Math. Phys. Eng. Sci. 2020, 476. [CrossRef] 
62. Vakula, D.; Raviteja, B. Smart Public Transport for Smart Cities. In Proceedings of the 2017 International Conference on Intelligent Sustainable Systems (ICISS), Palladam, India, 7-8 December 2017; pp. 805-810.

63. Bauza, R.; Gozalvez, J. Traffic congestion detection in large-scale scenarios using vehicle-to-vehicle communications. J. Netw. Comput. Appl. 2013, 36, 1295-1307. [CrossRef]

(C) 2020 by the authors. Licensee MDPI, Basel, Switzerland. This article is an open access article distributed under the terms and conditions of the Creative Commons Attribution (CC BY) license (http://creativecommons.org/licenses/by/4.0/). 